\title{
Mandibulofacial dysostosis
}

\author{
Hein Els, MB ChB, MFamMed, CCFP \\ Shaun Scheepers, MB BCh \\ Department of Diagnostic Radiology, Tygerberg Academic Hospital, Tygerberg, W Cape
}

Corresponding author: H Els (els.hein@gmail.com)

Two cases of children with Treacher Collins syndrome (mandibulofacial dysostosis) are presented, to illustrate the features of the syndrome. The cranial computed tomography (CT) scanning was performed to assist with surgical planning. Figs 1 and 2 demonstrate some of the features associated with the syndrome.

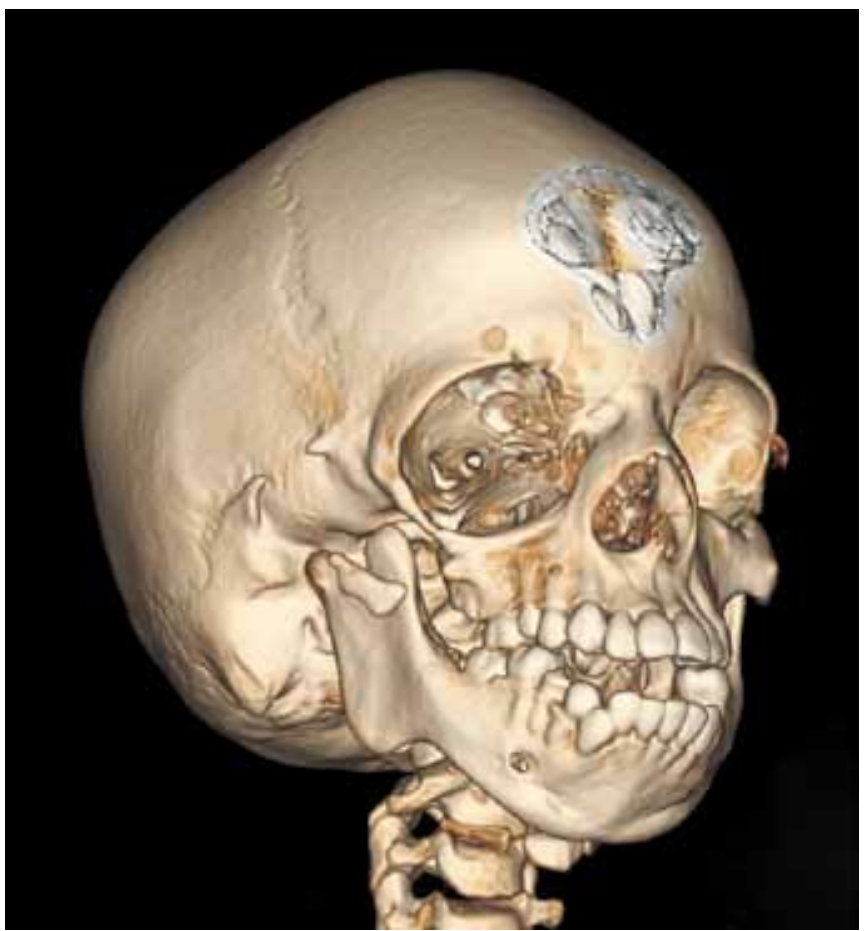

Fig. 1. A 10-year-old girl. The 3D image demonstrates hypoplastic zygomas with downward sloping orbits and atresia of the external auditory canals. The mandible is also hypoplastic with a concave inferior border. There is an artefact in the midline frontal.

The syndrome known as Treacher Collins, or Franceschetti-ZwahlenKlein, syndrome is a rare genetic disorder with an autosomal-dominant pattern of inheritance. It is named after the British ophthalmologist Edward Treacher Collins (1862 - 1932) who described the essential traits in 1900. ${ }^{1}$ This developmental disorder has an estimated prevalence of between 1 in 40000 and 1 in 70000 live births. ${ }^{2}$ In most cases, the diagnosis is evident at birth.

The features may range from unnoticeable to severe. There are various dysmorphic features and signs affecting the face, skull, ears, eyes, nose, mouth, throat and mental status. Among others, these include hypoplastic zygomas, downward sloping palpebral fissures,

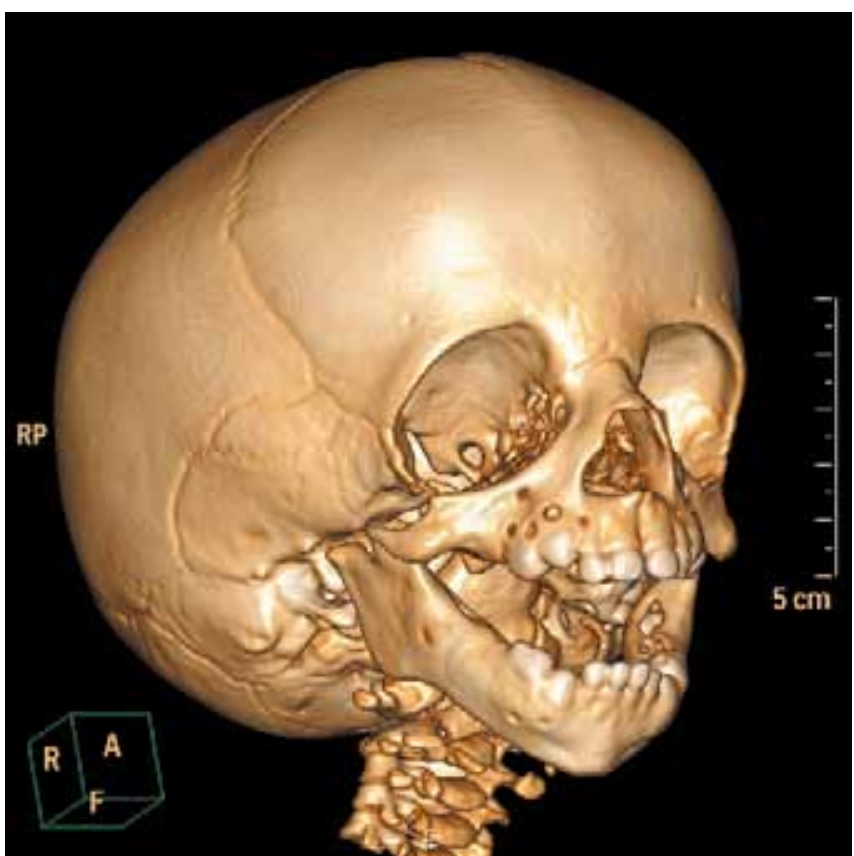

Fig. 2. An 11-month-old girl. The 3D image demonstrates the hypoplastic zygomas and mandibilar ramus. The orbits are down-sloping.

malformed pinnae, abnormalities of the external auditory canal (stenosis or atresia), maldevelopment of the ossicles, absence of middle ear and tympanic spaces, pharyngeal hypoplasia, deficient mandibular rami and a cleft palate. The inner ears are usually normal, but these children may have conductive hearing loss owing to the absence of the middle ears. Although persons with mandibulofacial dysostosis usually have normal intelligence, developmental delay may occur if the hearing loss is not diagnosed. The differential diagnosis includes acrofacial dysostosis, oculoauriculovertebral spectrum and X-linked dominant maxillofacial dysostosis. ${ }^{3}$ CT or magnetic resonance imaging (MRI) is usually pursued prior to any surgical intervention.

Treatment may require intubation after birth if the airway is compromised. The focus of the intervention is on symptom treatment and correction of anatomical deformities, which will inevitably require a multidisciplinary team approach with quite specific timing of interventions.

1. http://www.whonamedit.com/doctor.cfm/1393.html (accessed 3 November 2010).

2. Gorlin RJ, Cohen MM Jr, Hennekam RCM. Syndromes of the Head and Neck. 4th ed. Oxford, UK:

Oxford University Press, 2001

3. http://emedicine.medscape.com/article/946143-overview (accessed 3 November 2010). 